\title{
SERVIÇOS NA PAEP 2001 reconfigurando a agenda de pesquisas estatísticas de inovação
}

\author{
ROBERTO BERnARDES \\ VAGNER BESSA \\ ANDRÉ Kalup
}

\begin{abstract}
Resumo: Este artigo, que realiza uma abordagem teórica sobre a natureza e as singularidades do processo de inovação nos serviços e na indústria, baseia-se em análise empírica e utiliza os dados de inovação Paep 2001 captados pela Fundação Seade.

Palavras-chave: Indicadores setoriais de inovação. Indústria e serviços.

Abstract: This paper presents a theoretical approach over the nature and peculiarity of innovation process in Services and Industry sectors, based upon an empirical investigation using Paep 2001 datum gathered by Fundação Seade.

Key words: Sectoral innovation indicators. Industry and Services.
\end{abstract}

$\mathrm{O}$ s estudos sobre o papel das atividades de serviços no âmbito do processo de reestruturação produtiva vêm provocando intensa discussão sobre a natureza do processo de inovação entre suas atividades. Em que pese o avanço que essa discussão proporcionou na superação de certas concepções tradicionais - que associam os serviços apenas a pequenas empresas cujo core inovador não apresenta densidade tecnológica ou que entendem o setor como um bloco de atividades homogêneas dependente da disseminação de progresso técnico gerado pela indústria - há matizes importantes nesse processo de revisão sobre a natureza do processo de inovação.

Há estudos como os de Freeman et al. (1982) e Momigliano e Siniscalco (1986), que analisam comparativamente as experiências de países de industrialização avançada e constatam que este movimento está fortemente condicionado a um processo transacional de comple- mentaridade e interdependência estimulado pela dinâmica gerada pela indústria (que, aliás, tem criado uma grande demanda por serviços especializados e intensivos em informação e ciência). Já outros estudos recentes, desenvolvidos por Evangelista, Sirilli e Smith (1998), Bonden e Miles (2000), Howells (2000) e Kon (2004) relativizam a abordagem determinística entre indústria e serviços, apontando que, em várias dimensões, os segmentos de serviços apresentam estratégias e dinâmicas de inovação próprias em relação ao paradigma clássico de desenvolvimento industrial.

Isso não significa que o processo de reestruturação produtiva não seja relativamente ambíguo em relação ao setor terciário, sobretudo no que tange a seus aspectos "flexíveis". Afinal, se por um lado o rol dos chamados "serviços avançados" irrompe no tecido econômico como uma resultante do desenvolvimento empresarial e da cons- 
trução de competências especializadas, por outro, o processo de terceirização dá fôlego à expansão das atividades tradicionais baseadas em redes de subcontratação informais de grandes e pequenas empresas, como: vigilância, limpeza, conservação predial, alimentação, transporte, etc. Essa multiplicidade de encadeamentos empresariais e padrões técnicos reforçam a já reconhecida heterogeneidade do setor e não suprimem os elementos considerados "espúrios", ligados à "terceirização rudimentar".

No entanto, o que vem interferindo mais recentemente na discussão sobre o processo de inovação de serviços são as dimensões relativamente mais modernas do processo de crescimento do terciário. Em linhas gerais, a profunda heterogeneidade e a segmentação setorial do terciário são reconhecidas. Mais que isso, a nova geração de estudos sobre o papel das atividades de serviço no processo de inovação tecnológica confronta as abordagens tradicionais, que definem serviços como atividades pouco intensivas em tecnologia de baixa produtividade e qualificação de recursos humanos - tidos como usuários passivos do progresso técnico e dos conhecimentos gerados na indústria. Uma das mudanças mais importantes surgidas na última década diz respeito ao papel dos setores de serviços intensivos em informação, tecnologia e ciência nas chamadas "economias baseadas em conhecimento e aprendizado" (EBCAs). As evidências empíricas indicam um crescimento expressivo da participação relativa dos serviços intensivos em tecnologia na composição das estruturas econômicas internas e nos fluxos de comércio internacionais, assim como nas rotinas de inovação e aprendizado nas economias cêntricas.

$\mathrm{Na}$ verdade, a agenda de pesquisas internacionais no campo da economia ficou mais sensível ao contato de uma área que se convencionou chamar de "economia da inovação", assim abriu-se a oportunidade de exploração das relações desenvolvidas nesse segmento e suas articulações com a economia industrial e de inovação, por mais imbricadas que fossem. Com efeito, a idéia de uma economia da inovação aplicada ao setor de serviços inaugura uma abordagem com ampla pontencialidade analítica e reconhece a função estratégica desse setor na geração de renda e riqueza - e também nas trajetórias de inovação nas EBCAs. Um marco importante nessa direção foi a produção de informações estatísticas seriadas de inovação e P\&D por instituições públicas e privadas nos países centrais, tais como o Eurostat da OCDE (Organization for Economic Co-operation and Development). Há, também, as experiências de agências estatísticas internacio- nais ${ }^{1}$ para mensuração do processo de inovação no setor de serviços, que são uma prática relativamente recente.

No setor científico brasileiro, vem se consolidando cada vez mais uma nova agenda: estimulada pela implementação de pesquisas econômicas e sociais, ela demonstra preocupação com a função estratégica que a inovação pode ocupar no desenvolvimento e na competitividade da economia nacional. Até o final da década de 90, estudos e metodologias que visassem à construção de séries históricas sobre indicadores de inovação eram ações institucionais pouco exploradas nas pesquisas estatísticas. ${ }^{2}$

O esforço pioneiro nessa direção foi empreendido pela Associação Nacional de Desenvolvimento das Empresas Industriais - Anpei, que a partir de 1992 desenvolveu uma pesquisa orientada na experiência norte-americana da National Science Foundation, ${ }^{3}$ que consiste em uma base de indicadores empresariais de P\&D sobre a indústria brasileira. Logo depois, destaca-se a implementação da Pesquisa da Atividade Econômica Paulista - Paep, de 1996, realizada pela Fundação Sistema Estadual de Análise de Dados - Seade, que consagrou-se como uma pesquisa econômica estrutural que incorporava em seu projeto o primeiro levantamento sobre inovação realizado no Brasil. ${ }^{4}$ A Paep adotou o referencial conceitual recomendado pelo Manual de Oslo e teve como universo de investigação 40 mil empresas industriais localizadas no Estado de São Paulo. 5

Em 2001, o Instituto Brasileiro de Geografia e Estatística - IBGE, iniciou a série da Pesquisa Industrial de Inovação Tecnológica - Pintec, para a construção de indicadores nacionais da atividade de inovação tecnológica nas empresas industriais (DE NEGRI; SALERNO, 2005; KANNEBLEY JUNIOR; SILVEIRA PORTO; TOLDO PAZELLO, 2005).

Assim, o principal argumento sustentado nesta introdução é que, embora deva ser reconhecido o elevado esforço metodológico e empírico encetado pela academia e pelas instituições públicas, ${ }^{6}$ há um "objeto ausente" em grande parte dos estudos sobre inovação no Brasil: a formalização de uma agenda de pesquisas sobre a economia de inovação de serviços que construam um sistema de informações e permitam elucidar sua natureza e seu comportamento.

Consagra-se como objetivo deste texto analisar a experiência de implementação de uma primeira abordagem sobre o processo de inovação em serviços, aplicado pela nova tomada de campo realizada pela Paep 2001: para tanto, ele discute seus obstáculos metodológicos e 
conceituais, assim como seus resultados. O artigo inicia apresentando e confrontando as principais correntes teóricas sobre a economia de serviços a partir de uma visão crítica sobre este tema, introduzindo o debate contemporâneo sobre as teorias de inovação neste setor. A segunda parte discute teórica e conceitualmente os pontos de convergências e diferenças sobre a dinâmica de inovação entre a indústria e os serviços. A última parte, apresenta a experiência de aplicação do survey sobre inovação em empresas de serviços realizado pela Paep 2001.

\section{ABORDAGEM DA ECONOMIA DA INOVAÇÃO NOS SERVIÇOS}

Nos anos 90, a partir de uma perspectiva crítica às correntes teóricas filiadas as abordagens clássicas (FISHER,1935; CLARK, 1980) e pós-industrialista (TOURAINE, 1969; BELL, 1973) sobre a teorização e análise do crescimento do setor de serviços, foram sendo desenvolvidos novos estudos que tinham como objetivos identificar evidências sobre as relações de complementariedade, interdependência econômica e a dinâmica processual de inovação entre os setores da indústria e de serviços.

No cenário internacional, dois principais grupos lideram uma linha de estudos sobre a economia de serviços e a formulação de uma teoria de inovação mais consistente para este setor, quais sejam: o Voorburg Group e o STEP (Studies in Technology, Innovation and Economic Policy) Group (Quadro 1).

Estudos realizados por Gershuny e Miles (1983); Evangelista, Sirilli e Smith (1998); Bonden e Miles (2000); Howells (2000) têm enfatizado o papel estratégico exercido pelos serviços nas dinâmicas de inovação e no aumento das rotinas de P\&D nas economias baseadas em conhecimento. A partir da análise comparativa das experiências de países de industrialização avançada, os autores observam um aumento exponencial da participação relativa do setor terciário na sua estrutura econômica justificado na agregação de valor e conhecimento gerada pela oferta de serviços especializados e intensivos em informação e ciência. Tais analistas enfatizam que os serviços intensivos em conhecimento desenvolveram-se mais rapidamente no decurso dos anos 90 , em vários países membros da OCDE, e particularmente, nos EUA. ${ }^{7}$ Alguns dos fatores causais para o crescimento das economias baseadas em conhecimento e aprendizado (EBCAs) têm sido as economias e os serviços de informação. ${ }^{8} \mathrm{O}$ acesso às tecnologias da informação e comunicação - TICs ${ }^{9}$ e os processos de convergências tecnológicas, nos quais o exemplo da telemática é mais evidente, desenvolveramse mais aceleradamente no decurso dos anos recentes.

Reconhecendo-se a preservação de um alto grau de heterogeneidade e assimetria nos serviços modernos, au-

QUADRO 1

Núcleos de Estudos Internacionais sobre a Economia de Serviços e Inovação

Instituído em 1986 por iniciativa do Statistics Canada e o United Nations Statistical Office - UNSO, para suprir a lacuna no campo de produção e monitoramento de estatísticas no setor de serviços. Seu principal objetivo é ser um fórum informal e permanente de troca de idéias a respeito de estatísticas de serviços, promovendo encontros internacionais anuais. Disponivel em: <http://www4.statcan.ca/english/voorburg/>.
Sediado em Oslo, na Noruega, coordena o projeto Services in Innovation in Services - SI4S, financiado pela Comissão Européia e objetiva desenvolver conceitos, evidências empíricas e sugestões para ações práticas sobre a função dos serviços no sistema de inovação. Além do SI4S, o grupo coordena o Indicators and Data for European Analysis - IDEA que busca realizar estudos dos indicadores de inovação tecnológica e criar novos indicadores. Outro importante projeto desenvolvido no âmbito do STEP é o KISA (Knowledge Intensive Service Activities) conduzindo sob os auspícios da OCDE pelo grupo TIP (Group on Technology and Innovation Policy) subordinado ao Comitê de CSTP (Science and Technology Policy). Participam neste projeto países como Austrália, Finlândia, Coréia do Sul, Nova Zelândia, Espanha, Irlanda e Noruega. Disponivel em: <http:/www.step.no/Projectarea/IDEA/index.htm>. 
tores como Evangelista, Sirilli e Smith (1998), Howells (2000) e Kon (2004) levantam um conjunto de questões que são fundamentais para a compreensão e o avanço dos estudos sobre inovação nos serviços, quais sejam:

- as fronteiras entre as atividades inter e intra-setoriais entre a indústria e os setores de serviço tornaram-se mais tênues devido à elevação da segmentação gerada pelas assimetrias tecnológicas e ao adensamento dos fluxos de cooperação de conhecimento e informações estratégicas;

- há uma nítida tendência de redução dos ciclos de desenvolvimento e de vida de produtos industriais e de serviços: ela é estimulada pela aceleração das mudanças tecnológicas e pelo uso de TICs. Esta maior atividade de inovação de produto e processo na indústria tende a gerar uma pressão mais intensa por novos critérios de funcionamento corporativos gerenciais, de qualidade, produtividade e de inovação nos serviços industriais;

- os novos padrões de consumo são caracterizados pela alta volatilidade, customização e complexificação de produtos e serviços;

- há expedientes agressivos de terceirização e/ou subcontratação de atividades corporativas internas, como os utilizados por organizações que buscam focalizar suas estratégias em competências centrais ou as que transformam custos fixos em variáveis, aumentando suas margens de flexibilidade operacional. Neste sentido, observa-se o crescimento da terceirização dos serviços especializados de alto conteúdo de conhecimento como design, engenharia de projeto, processo e sistemas;

- as novas estratégias competitivas baseadas na inovação e nas dinâmicas de globalização e hierarquização das cadeias de valor impõem novos paramentos de logística, planejamento, P\&D, até mesmo com maiores oportunidades de internacionalização para alguns tipos de serviços, sobretudo aqueles de maior intensidade tecnológica;

- ainda que o setor secundário exerça forte força gravitacional no setor terciário, em várias dimensões, os segmentos de serviços apresentam dinâmicas econômicas e comerciais próprias em relação o desenvolvimento industrial.

A partir destas premissas, Miles (2001) identificou três movimentos de transformações estruturais que perpassam a economia de serviços, cuja compreensão é crucial para a elaboração de um processo de inovação setorial. De modo sintético, esses movimentos estão associados aos resultados dos diferentes tipos setoriais de regimes, especificidades e trajetórias tecnológicas dos serviços, a saber:
- serviços físicos: são aqueles cujos impactos de transformação são derivados de TICs e atuam diretamente na forma de preservação intertemporal e/ou de transporte de serviços, bens e pessoas - tomando-se "transporte" como "realocação através do espaço". Um exemplo a ser citado é o comércio atacadista e varejista que combina simultaneamente os serviços de logística para distribuição, movimentação e estocagem de produtos (com o uso de alguns serviços de informação, como Global Position Sensoriament - GPS). Indústrias como a automobilística e alimentícia são ilustrações precisas dessas tendências, pois são usuárias intensas desses serviços e acabam por influir no processo de inovação desses serviços.

- serviços personalizados: podem ser divididos em serviços comunitários e sociais, como nas áreas de saúde e educação. Assim como nos serviços de consumo privado (salões de beleza e clínicas de estética) ou os chamados home comforts (hotéis, flats, etc.) a difusão de TICs e inovações organizacionais tem permitido um avanço considerável na integração dos processos gerenciais, na qualidade e produtividade desses serviços. Especialmente no campo da saúde, os benefícios que surgem a partir de pesquisas e desenvolvimentos públicos e industriais na área de instrumentação cirúrgica - como o laser e a cosmecêutica (fusão dos campos de pesquisa da farmacêutica com a cosmética) - têm proporcionado impactos relevantes na oferta destes serviços.

- serviços informacionais: reúnem basicamente três tipos distintos de atividades - mídia de massa (mass media) caracterizada pela distribuição padronizada em escala de informações audiovisuais. São exemplos, os cinemas, televisão, etc.; infomídia, sua diferença em relação ao segmento de mídia de massa, é o fato de as empresas distribuírem informações customizadas e personalizadas em larga escala. São exemplos os serviços de telefonia celular com imagens, informações financeiras on-line, etc.; serviços intensivos em conhecimento, são aqueles onde o conhecimento e a informação especializada, a expertise profissional na capacidade de codificação, interpretação e análise sejam fatores cruciais para sua oferta. O impacto relativo das TICs, dos softwares de simulação, análise e desenvolvimento são significativos na oferta destes serviços. São exemplos, as empresas de engenharia e P\&D, arquitetura, engenharia, consultorias, atividades de marketing, entre outras.

Miles (1995) ainda confere especial importância a um núcleo de serviços intensivos em inovação denominados 
$\mathrm{KIBS}^{10}$ (knowledge intensive business services) pois, segundo o autor, são os segmentos que vêm apresentando taxas rápidas de crescimento e rendimento econômico nas EBCAs. Segundo Nählinder (2002), esses serviços têm como principais características uma lógica de funcionamento próxima à da indústria, alta performance na geração de renda, divisas e valor adicionado e uma forte tendência à internacionalização das suas atividades negociais, atuando como verdadeiros agentes facilitadores de inovação. Sua dinâmica concorrencial está baseada na disseminação de novos padrões tecnológicos e de TICs para os serviços, que atuam com fontes difusoras da inovação. Criam, produzem, desenvolvem e difundem conhecimentos para outras firmas e setores da economia; utilizam intensivamente recursos humanos de alta qualificação; são formados por empresas desenvolvedoras e usuárias de inovações e TICs; realizam e vendem serviços de P\&D; apresentam taxas elevadas de crescimento na economia; e, por oferecerem serviços customizados, apresentam alta interação produtor-usuário (intensiveinformation e intensive-client). Os KIBS podem ser agrupados em dois conjuntos:

- Professional KIBS (P-KIBS): são serviços usuários de novas tecnologias, direcionados ao conhecimento técnico e administrativo (segmentos de engenharia, design, arquitetura, marketing, publicidade, consultorias financeiras e jurídicas, P\&D em ciências sociais e naturais, consultoria em gestão empresarial, entre outros);

- Technological KIBS (T-KIBS): são serviços focados em novas tecnologias (redes de informática, serviços de telecomunicações, entre outros).

\section{PADRÕES DE CONVERGÊNCIA ENTRE A INDÚSTRIA E AS EMPRESAS DE SERVIÇO QUANTO A INOVAÇÃO TECNOLÓGICA}

Como já evidenciado, o que mais tem interferido no debate sobre o comportamento da inovação tecnológica nas empresas de serviço é o fato de que o avançado processo de crescimento do terciário vai ganhando a cada dia maiores dimensões. Alguns autores salientam a existência de processos de convergência entre os padrões de funcionamento das empresas de serviço e os da atividade manufatureira - o que possibilita a análise de diversos setores dentro de um campo normativo comum. Uchupalanan (1998), Sundbo e Gallouj (2000) observam um incremento da diversidade das trajetórias inovadoras e um movi- mento de convergência nas dinâmicas de inovação entre o setor de serviços e a indústria. Um fator que desempenha papel central nesse processo é a difusão das novas TICs. A digitalização e a expansão da infra-estrutura de telecomunicações implicam em transformações tecnológicas substanciais das atividades vinculadas ao uso e difusão de informações. Como são mudanças específicas a algumas atividades terciárias, elas passam a ter características de "Serviços Intensivos em Tecnologia" (Technology Intensive Services), e, quando não, de "líderes em investimentos tecnológicos típicos de redes" (bancos, serviços financeiros, atividades audiovisuais, etc.). Esse processo tornaria possível a aplicação de técnicas típicas da produção em escala industrial massificada em vários segmentos do setor de serviços, facilitando a superação de certos entraves para a produção. Outro argumento utilizado ressalta uma convergência no modus operandi da indústria e os serviços, com o intercâmbio de padrões concorrenciais, tecnológicos e organizacionais entre esses dois grandes segmentos. Enquanto as atividades industriais passam a ser mais dependentes dos insumos intangíveis, os serviços especializados e a mão-de-obra qualificada para o incremento da competitividade, assim como alguns segmentos do setor de serviços tornam-se mais dependentes de investimentos em recursos físicos (sobretudo investimentos em redes de logística, transporte e telecomunicações), desenvolvem produtos padronizados dentro de padrões "fordistas", baseados em economias de escala, e intensificam sua participação no comércio internacional, tal como pode ser verificado entre as atividades especializadas de consultoria, pesquisa e desenvolvimento, propaganda e marketing e software (BONDEN; MILES, 2000) (Quadro 2).

Em que pese esse processo de difusão de TICs e a convergência entre os padrões técnicos da indústria e dos serviços, as dificuldades metodológicas para a construção de um arcabouço conceitual visando a elaboração de um conjunto coerente de indicadores de inovação nesse setor não são desprezíveis, pois há diferenciações que impedem um enfoque unificado. Marklund (2000) destaca que as abordagens clássicas sobre inovação baseiam-se em modelos industriais, em que os indicadores são tratados dentro de uma ótica estritamente tecnológica, obtidos a partir de resultados com investimentos tangíveis, gastos de P\&D e patentes. Apesar de serem capazes de refletir em parte do processo de inovação nos segmentos de serviços, são ainda inapropriados como medida global. ${ }^{11}$ 
QUADRO 2

Convergência e Diferenciação entre os Serviços e a Indústria

\begin{tabular}{|c|c|c|}
\hline Características & Serviços & Indústria \\
\hline \multicolumn{3}{|l|}{ Da Produção } \\
\hline Estrutura e Tecnologia & $\begin{array}{l}\text { Crescimento no nível de equipamentos de TICs; } \\
\text { serviços intensivos em tecnologia. }\end{array}$ & $\begin{array}{l}\text { Intensivo uso de TICs, similar ao de serviços, } \\
\text { entretanto diferenciado no tipo de tecnologia. }\end{array}$ \\
\hline Habilidade (trabalho) & $\begin{array}{l}\text { Caracteristicamente técnico. Redução da equipe } \\
\text { de executivos e estratégias de captação externa. }\end{array}$ & $\begin{array}{l}\text { Produção intensiva em conhecimento; alta } \\
\text { qualificação; existência de equipe executiva; } \\
\text { otimização e captação externa. }\end{array}$ \\
\hline Organização do Trabalho & $\begin{array}{l}\text { Padronização das tarefas, usando novas } \\
\text { tecnologias e técnicas de organização. }\end{array}$ & $\begin{array}{l}\text { Novas formas de organização do trabalho } \\
\text { (ganho de autonomia). }\end{array}$ \\
\hline Aspectos da Produção & $\begin{array}{l}\text { Economias de escala; produção em massa } \\
\text { buscado em outros serviços. }\end{array}$ & $\begin{array}{l}\text { Flexibilidade; redução de estoques através } \\
\text { de métodos gerenciais (just-in-time). }\end{array}$ \\
\hline Organização Setorial & $\begin{array}{l}\text { Tendência ao crescimento de grandes empresas; } \\
\text { empresas globais. }\end{array}$ & $\begin{array}{l}\text { Empresas altamente especializadas, subcon- } \\
\text { tratando outras atividades; empresas globais. }\end{array}$ \\
\hline \multicolumn{3}{|l|}{ Do Produto } \\
\hline Natureza do Produto & Novos serviços incorporados de TICs. & $\begin{array}{l}\text { Produtos de curto ciclo de vida (maior varieda- } \\
\text { de, sustentável em estoques de curto período). }\end{array}$ \\
\hline Aspectos do Produto & $\begin{array}{l}\text { Produtos padronizados, aplicáveis para vários } \\
\text { serviços; "personalização em massa". }\end{array}$ & $\begin{array}{l}\text { Produção flexível permitindo "personalização } \\
\text { em massa" de vastos produtos. }\end{array}$ \\
\hline Propriedade Intelectual & $\begin{array}{l}\text { Uso de direitos autorais (software), produtos } \\
\text { patenteáveis. }\end{array}$ & Produtos de difícil proteção (software). \\
\hline \multicolumn{3}{|l|}{ Do Consumo } \\
\hline Entrega do Produto & $\begin{array}{l}\text { Uso de novos meios para entrega (serviços de } \\
\text { informações especiais, uso da Internet, etc.). }\end{array}$ & $\begin{array}{l}\text { Proximidade entre produção e mercado, } \\
\text { usando novos sistemas de TICs. }\end{array}$ \\
\hline Atuação com o Consumidor & $\begin{array}{l}\text { Consumidor mais conectado por meio do sistema } \\
\text { de TICs do que diretamente com a equipe. }\end{array}$ & $\begin{array}{l}\text { Maior relação com os usuários. Crescente } \\
\text { variedade de serviços auxiliares, como } \\
\text { marketing e pós-vendas. }\end{array}$ \\
\hline Organização do Consumo & $\begin{array}{l}\text { Uso de novos meios para separação de consumo } \\
\text { e produção. }\end{array}$ & $\begin{array}{l}\text { Financiamento de equipamentos. Fornecedores } \\
\text { orientados para "pacote de serviços" ao invés } \\
\text { de simples bens ou utilidades. }\end{array}$ \\
\hline \multicolumn{3}{|l|}{ De Mercado } \\
\hline Organização do Mercado & $\begin{array}{l}\text { Privatização de serviços públicos. Competição global } \\
\text { em serviços anteriormente protegidos. }\end{array}$ & $\begin{array}{l}\text { Mercado de empresas. Privatização de } \\
\text { empresas. }\end{array}$ \\
\hline Regulamentação & $\begin{array}{l}\text { Des/Regulamentação; nova regra no comércio de } \\
\text { serviços. Crescimento da importância com as } \\
\text { padronizações. }\end{array}$ & $\begin{array}{l}\text { Crescimento da regulamentação ambiental. } \\
\text { Importância das padronizações. }\end{array}$ \\
\hline Marketing & $\begin{array}{l}\text { Maior esforço em marketing; participações em feiras } \\
\text { e exposições. }\end{array}$ & Marketing orientado e serviços ao usuário. \\
\hline
\end{tabular}

Fonte: Bonden; Miles (2000), tradução dos autores.

Segundo o autor, as atividades de inovação no setor de serviços podem ser orientadas para o desenvolvimento tecnológico - como, na área de informática, no fornecimento de software e/ou na incorporação de aplicações de serviços de valor agregado de telecomunicações nas áreas de entrega ou logística. Mas as inovações mais comuns no setor não possuem viés tecnológico e podem ser realizadas com o objetivo de aperfeiçoar a interface entre con- 
sumidores e o diagnóstico de variáveis que determinam o perfil psicológico do consumidor. Isto implica a mudança do design do produto ou serviço e torna a difusão de patentes pouco significativa como retrato das trajetórias de modernização. Ao mesmo tempo, constata que as empresas inovadoras não realizam atividades de $P \& D$ e que as que o fazem não desenvolvem pesquisas em departamentos formais ou especializados.

Marklund (2000), baseando-se em pesquisas européias sobre inovação implementadas no âmbito da OCDE no setor de serviços, concluiu que grande parte das empresas inovadoras não tem laboratórios formalmente organizados, como tradicionalmente existem na indústria sendo que os esforços de $\mathrm{P} \& \mathrm{D}$ não possuem uma regularidade sistemática e têm sua origem em outros departamentos das empresas, geralmente nas áreas de marketing. No caso das pesquisas de inovação strictu sensu no setor de serviços, Gallouj e Weinstein (1997) advertem que elas se apropriam, sem as devidas mediações, das mesmas bases metodológicas que descrevem o processo de inovação tecnológica na indústria. Segundo Hauknes (1999), a inovação está tão difundida no setor de serviços como na manufatura, porém os conceitos de inovação desenvolvidos sobre as análises da indústria não se aplicam diretamente sobre os serviços. Isso acontece porque, nas relações de serviços, o produto não tem necessariamente um formato físico - o que torna quase impossível transpor para este tipo de produção os mesmos conceitos que se aplicam à produção de escala industrial massificada ou customizada. Essa constatação instaura um desafio metodológico para o desenvolvimento de estudos e políticas voltadas para o setor serviços e tem suscitado um intenso debate no meio acadêmico. Um pressuposto inicial que motivou vários pesquisadores foi o fato de os serviços serem vistos como consumidores da inovação gerada no setor manufatureiro, por isso, os instrumentos de captação e mensuração da inovação foram formulados para medir as variáveis industriais.

Meanwhile, Sirilli e Evangelista (1998, apud HIPP; TETHER; MILES, 2000), enumeram o grau de dificuldades para a construção de uma metodologia unificada entre indústria e serviços para as pesquisas de inovação nos seguintes termos:

- a primeira delas decorre das dificuldades que as empresas têm de distinguir entre inovações de produto e de processo - dado que as atividades de serviços apresentam co-determinação simultânea entre produção e consumo, não é possível, como na indústria, estabelecer claramente uma diferença substancial entre o produto resultante da inovação e os processos necessários para sua realização; - a segunda característica está vinculada à natureza intangível dos serviços e à inexistência de propriedades de estocagem. Nesse sentido, na produção dos serviços não há a possibilidade de existência independente do ato de produtores ou usuários, tal como ocorre na indústria;

- a terceira deriva do papel central que os recursos humanos desempenham para a provisão dos serviços. Embora uma parte das atividades vinculadas ao setor terciário apresente alta dependência de recursos e instalações físicas - assim como acontece na indústria - nas atividades que alcançam escala ou que operam em rede, o processo de inovação é altamente dependente da forma de organização e dos conhecimentos e habilidades pertencentes à força de trabalho, como por exemplo nos serviços de telecomunicações e transportes, nas atividades financeiras e no comércio varejista;

- outra questão é o fator organizacional, dado que o aumento da eficiência para a provisão dos serviços não está vinculado a fatores tecnológicos strictu sensu, mas pode decorrer de novas formas de gestão dos recursos essenciais para o processo de inovação - como a implementação de novas técnicas de gestão e a organização e distribuição dos estoques de informações e de conhecimento disponíveis.

Howells (2000) destaca outros elementos que historicamente têm distinguido a manufatura e os serviços em termos de trajetórias tecnológicas, dinâmica de funcionamento e estrutura do setor, mesmo considerando que algumas das especificidades que demarcavam a fronteira entre os dois setores foram se atenuando ao longo do tempo. Por esse motivo, Howells (2000) alerta que o esforço para adaptar o modelo de captação de informações, criado para a manufatura para mensurar a inovação em serviços, pode vir a ser uma armadilha. Um dos fatores de diferenciação é a "orientação tecnológica". Na manufatura, ela é liderada pela atividade de ciência e tecnologia; já nos serviços, pelos consumidores. Devido a essa interface entre produção e consumo de serviços, uma grande parte das atividades de inovação no setor volta-se para a adaptação/customização dos serviços às necessidades dos usuários. Em muitos casos, essas atividades são inovativas, apesar de incorporarem um conteúdo tecnológico limitado. Nesse mesmo sentido, Evangelista, Sirilli e Smith (1998) lembram ainda que a proximidade entre a produção e o consumo no setor de serviços dificulta 
a distinção entre produto e processo. Conseqüentemente, isto faz com que a distinção entre a inovação de produtos e processos seja menos clara se comparada com a usada no setor industrial.

Outras diferenciações dizem respeito às fontes de pesquisa e de geração de inovação: enquanto na manufatura elas tendem a ser internas à empresa, no setor de serviços elas são sobretudo externas. Na manufatura, a propriedade intelectual é protegida pela patente; já no setor de serviços ela é protegida pelos direitos autorais (copyright) sendo que este último é um recurso bem menos eficaz do que o primeiro.

Assim, o impacto gerado pelo desenvolvimento tecnológico na produtividade do trabalho seria alto na manufatura e baixo nas empresas de serviço. Nestas, os ciclos de vida e de segredo são mais curtos do que os presenciados na indústria. Outros aspectos que diferenciam o setor de serviço da indústria são as condutas de orientação tecnológica para P\&D, os ciclos mais longos de pesquisa, os impactos relativamente menores e menos encadeados do que os produzidos pela indústria.
A título de ilustração, é interessante notar que Howells (2000) apresenta um esforço para a sistematização sobre diferentes aspectos do processo de convergência e diferenciação das trajetórias de inovação nos serviços e na indústria (Quadro 3).

\section{SURVEYS DE INOVAÇÃO EM SERVIÇOS EM PAÍSES EM DESENVOLVIMENTO: DESAFIOS MÉTRICOS E CONCEITUAIS}

As experiências das agências estatísticas internacionais para mensuração do processo de inovação no setor de serviços são relativamente recentes e revelam-se bastante complexas, face a todas as questões expostas anteriormente. As primeiras tentativas de realizar uma quantificação dos processos de inovação no âmbito da OCDE ocorreram em meados da década de 80 , mas a iniciativa de estabelecer um framework conceitual, que possibilitasse estudos comparativos baseados em pesquisas em larga escala, foi impulsionada pela experiência dos países escandinavos (Dinamarca, Finlândia, Noruega e Suécia).

QUADRO 3

Características de Diferenciação dos Regimes de Inovação na Indústria e nos Serviços

\begin{tabular}{|c|c|c|c|}
\hline Características & Indústria & Serviços & Status \\
\hline $\begin{array}{l}\text { 1. Direitos de Propriedade } \\
\text { Intelectual }\end{array}$ & Forte: patentes & Fraco: direitos autorais & Corrente, forte \\
\hline 2. Orientação Tecnológica & $\begin{array}{l}\text { Avanço tecnológico; liderança } \\
\text { científica e tecnológica }\end{array}$ & $\begin{array}{l}\text { Avanço tecnológico; liderança } \\
\text { fornecedor/cliente }\end{array}$ & Histórico, declinante \\
\hline $\begin{array}{l}\text { 3. Pesquisa / Inovação Provedor e } \\
\text { Fornecedor }\end{array}$ & Internamente & Provindo externamente & $\begin{array}{l}\text { Declinante; convergindo na } \\
\text { indústria e serviços }\end{array}$ \\
\hline 4. Força Produtiva & Alto impacto & Baixo Impacto & $\begin{array}{l}\text { Corrente, potencialmente } \\
\text { declinante }\end{array}$ \\
\hline 5. Ciclos de Inovação & Curto e médio & $\begin{array}{l}\text { Longo (exceto ao serviços de } \\
\text { informática) }\end{array}$ & Declinante, fraco \\
\hline 6. Características do Produto & Tangível, de fácil estocagem & Intangível, de difícil estocagem & Declinante, médio \\
\hline 7. Internacionalização & $\begin{array}{l}\text { A atividade de exportação atrai } 0 \\
\text { IDE (1) }\end{array}$ & $\begin{array}{l}\text { A entrada de IDE proporciona a } \\
\text { exportação }\end{array}$ & Corrente, médio \\
\hline 8. Dimensão & Nacional => global & Regional => nacional => global & $\begin{array}{l}\text { Declinante; serviços } \\
\text { expandindo-se na } \\
\text { internacionalização }\end{array}$ \\
\hline
\end{tabular}

Fonte: Adaptação de Howells (2000).

(1) IDE = Investimento Estrangeiro Direto. 
O Manual de Oslo de 1992 (revisado posteriormente em 1996) foi desenvolvido pela OCDE, em conjunto com o Eurostat (Statistical Office of the European Communities) e do European Innovations Monitoring System. Seu objetivo era harmonizar a coleta e as análises de levantamentos sobre inovação na Europa, com base no principal sujeito do processo inovativo: as empresas. Com o apoio do Eurostat, foram revisados os conceitos de inovação tecnológica e sua metodologia de mensuração. A primeira pesquisa de inovação baseada no Manual de Oslo foi realizada em 1993 (para o período-base 1992-93): o Community Innovation Survey - CIS-I. Naquele levantamento, foram incluídas aproximadamente 40.000 empresas de treze países europeus. ${ }^{12} \mathrm{Na}$ revisão de 1996, não foram feitas mudanças estruturais, mas foi conferida grande ênfase à orientação dos procedimentos de coleta das informações relevantes para a promoção de políticas e para as características dos estudos da inovação. Definiu-se mais precisamente a distinção entre as inovações tecnológicas e aquelas puramente estéticas e organizacionais, identificando com maior rigor a origem, o principal agente da inovação e o nível de originalidade da inovação para o mercado.

O segundo European Community Innovation Survey CIS-II - tornou-se a primeira sistematização internacional de indicadores sobre o comportamento da inovação tecnológica das empresas de serviços, abordando períodos entre 1994 e 1996. Os segmentos pesquisados foram o comércio atacadista; transporte; telecomunicações; serviços financeiros; serviços de computador (nos quais os softwares se incluem); e os serviços técnicos. O CIS-II que se referia ao período 1994-96, aconteceu em 1998 e compreendeu a resposta de aproximadamente 55.000 empresas dos setores manufatureiros e de serviços de 16 países europeus. Em 2002, foi iniciado o terceiro Community Innovation Survey - CIS-III, com coletas referentes ao período 1998-2000.

Na Europa, muitos experts têm criticado o tema, reconhecendo as limitações dos levantamentos sobre inovação baseados na metodologia do Manual de Oslo.

Mesmo após as revisões metodológicas decorrentes do processo de discussão da CS I e II, autores como Marklund (2000) e Meanwhile, Sirilli e Envangelista (1998, apud HIPP; TETHER; MILES, 2000) argumentam que os serviços apresentariam determinadas especificidades que se traduziriam em obstáculos adicionais para a elaboração de metodologias e instrumentos para uma mensuração adequada dos processos de inovação por meio de levantamentos estatísticos. Como no setor de serviços os levantamentos de inovação baseados na indústria teriam uma abordagem puramente tecnológica, deixariam de captar processos organizacionais de inovação importantes. Para eles, as análises dos indicadores de inovação deveriam ser complementadas com informações sobre investimentos em recursos intangíves, como: desenvolvimento e aquisição de softwares; gastos com treinamento em recursos humanos; estratégias de marketing para exploração de novos mercados; marketing de novos produtos e serviços; uso de tecnologias de informação; gestão de novas arquiteturas organizacionais; políticas de remuneração ou compensação por competências individuais.

$\mathrm{Na}$ América Latina, no âmbito da Ricyt - Red Iberoamericana/Interamericana de Indicadores de Ciencia y Tecnología - tem sido desenvolvido um amplo debate metodológico sobre a necessidade de revisão das recomendações do Manual de Oslo para os critérios de inovação. ${ }^{13}$ Esta vertente de autores latinos defende a necessidade de uma distinção entre as mudanças organizacionais (na produção ou na inclusão de estratégias de marketing e de inteligência de mercado, uma vez que elas são elementos críticos para a inovação) e as nãoinovações tecnológicas.

Duas especificidades dos sistemas de aprendizado do continente foram explicitamente consideradas nessa versão latino-americana intitulada Manual de Bogotá: uma é o fato de que, historicamente, a inovação dessas economias baseia-se mais nos processos de difusão tecnológica por aquisição de tecnologia incorporada do que em rotinas de P\&D; outra é que, nesses sistemas, há a presença considerável de multinacionais estrangeiras que atuam como agentes importantes do processo de mudança tecnológica e de captação de recursos para inovação. Apesar dos esforços, muitas das críticas ao Manual de Oslo não foram superadas. Mas nem por isso esse manual deixou de ter o status de referencial metodológico de inovação para a América Latina.

As pesquisas sobre organização de $P \& D$ e inovação no Brasil têm reafirmado essas proposições e concluem que a estratégia de inovação deve ser integrada, necessariamente, à

estratégia comercial, à proteção da propriedade intelectual, aos marcos legais e regulatórios, às capacidades de produzir. Por outro lado, é possível ter uma estratégia inovadora sem ter necessariamente uma predominância do vetor tecnológico (FURTADO, 2004).

Existem até mesmo inovações que prescindem de um peso relevante da dimensão tecnológica: este é um ele- 
mento importante para entender o processo de inovações e aprendizagem em outros setores - particularmente no setor de serviços (FURTADO, 2004).

Nesse contexto, a Fundação Seade realizou a primeira pesquisa de inovação tecnológica por meio da Paep 1996. Entretanto, a pesquisa limitou-se a captar os processos de inovação na indústria, dado que o setor de serviços não foi investigado sob essa ótica. A segunda versão da pesquisa, realizada em 2001, suprimiu essa lacuna, realizando uma abordagem pioneira sobre a inovação no setor de serviços, dentro de um amplo espectro temático. ${ }^{14}$ Foram pesquisadas quase 21 mil empresas do Estado de São Paulo com 20 ou mais funcionários. Os dados foram colhidos entre julho de 2002 e junho de 2003, permitindo a análise de diversos segmentos da atividade econômica paulista nesse setor, durante o período 1999-2001. ${ }^{15}$

A primeira alteração metodológica refere-se à ampliação do âmbito da pesquisa. Em 1996, esse tema foi investigado apenas no setor da indústria geral (extrativa e transformação) e, em 2001, englobou todos os setores da pesquisa (indústria geral, indústria da construção, comércio de mercadorias, serviços e bancos).

A segunda principal modificação da pesquisa consiste na definição e classificação da inovação. Na Paep 2001, o indicador de inovação tecnológica foi definido a partir de uma abordagem mais restrita e seletiva, considerando inovadora a empresa que introduziu um produto (bem ou serviço) tecnologicamente novo ou significativamente aperfeiçoado, que tenha sido novo não apenas para a empresa, mas também para o mercado nacional. A introdução dessa questão permite elaborar um indicador de inovação mais seletivo entre as empresas classificadas como inovadoras. A referência conceitual e metodológica da Pesquisa de Inovação Tecnológica na Paep teve como base o Oslo Manual: proposed guidelines for collections and interpreting innovation data (1997). As alterações introduzidas visaram a atualizar e harmonizar a pesquisa de inovação com a experiência do modelo recomendado pelo Eurostat, consagrado na terceira versão da Community Innovation Survey (CIS-III). O tema "Pesquisa e Desenvolvimento - P\&D" foi investigado em conjunto com o levantamento dos dados de inovação tecnológica, exceto para os setores de comércio e bancos.

No caso específico do levantamento sobre inovação no setor de serviços, foram considerados apenas os aspectos tecnológicos e reproduzida a mesma a base conceitual aplicada à indústria, com pequenas adaptações para o setor terciário. Ainda que esse procedimento reproduza as limitações das pesquisas de inovações em serviços, como já fora salientado na literatura internacional, permite construir um amplo panorama da economia do Estado de São Paulo, com comparações intersetoriais e intrasetoriais dentro do mesmo arcabouço metodológico. Por outro lado, a Paep 2001 tem um escopo mais amplo que os surveys de inovação norteados pelo Manual de Oslo aplicados na OCDE, no Canadá ou na Austrália, pois capta informa-

\section{QUADRO 4}

Marco Conceitual e Exemplos de Inovação em Serviços na Paep 2001

\begin{abstract}
Inovação Tecnológica
A inovação tecnológica corresponde à introdução no mercado de um serviço ou produto novo ou significativamente aperfeiçoado para empresa, ou à implementação de um processo novo significativamente aperfeiçoado que tenha sido novo não apenas para a empresa, mas também para o mercado nacional. A inovação baseia-se em resultados do esforço de desenvolvimento de novas tecnologias ou novas combinações de tecnologias já existentes.
\end{abstract}

\section{Exemplos:}

- Sistemas de automação de abastecimento para indústria;

- Desenvolvimento de software para gestão operacional de frotas de veículos rodoviários;

- E-commerce;

- Web banking - transações financeiras com clientes;

- LivDev, Sistema de colaboração empresa/cliente para projetos de integração e desenvolvimento de sistemas.
Não-Inovação Tecnológica

Não são consideradas inovações tecnológicas mudanças puramente gerenciais ou organizacionais (como implementação de técnicas e conceitos avançados de gerenciamento, organização e marketing) e mudanças superficiais na prestação de serviços e no conceito de produção ou serviços já existentes. Também não deve ser considerada como inovação tecnológica, a introdução de serviços ou processos que não demandem uso de tecnologia nova.

\section{Exemplos:}

- Garantia de produtos

- Ampliação de produtos e serviços já realizados anteriormente

- Introduções de pagamentos por fax

- Mudanças administrativas ou organizacionais que não demandem o uso de tecnologia

- Introdução de páginas na Internet que visem puramente a divulgação da empresa e não disponham de recursos para comunicação interna, entre a empresa e seus clientes e/ou fornecedores. 
QUADRO 5

Indicadores e Variáveis para Análise da Inovação e Capacitação Tecnológica na Paep 2001

\begin{tabular}{|c|c|}
\hline Classes de Indicadores & Variáveis de Análise \\
\hline Inovação Tecnológica & $\begin{array}{l}\text { - Inovação de produto ou processo para o mercado; principal agente da inovação; distribuição } \\
\text { percentual de produtos novos na receita de vendas da empresa; principais fontes de inova- } \\
\text { ção; entre outras }\end{array}$ \\
\hline Atividades de P\&D & $\begin{array}{l}\text { - Rotinas sistemáticas de P\&D; subcontratação de atividades de P\&D; número de pessoas } \\
\text { alocadas à P\&D, entre outras }\end{array}$ \\
\hline $\begin{array}{l}\text { Aquisição de Tecnologia Incorporada } \\
\text { Aquisição de Tecnologia Desincorporada }\end{array}$ & $\begin{array}{l}\text { - Despesas com aquisição em máquinas e equipamentos nacionais e estrangeiros } \\
\text { - Despesas com royalties e assistência técnica local e estrangeira }\end{array}$ \\
\hline $\begin{array}{l}\text { Investimentos em Ativos Intangíveis } \\
\text { Capacitação em Gestão de Operações } \\
\text { Corporativas }\end{array}$ & $\begin{array}{l}\text { - Investimentos em softwares, copyright, marcas, patentes e franquias } \\
\text { - Uso de softwares de gestão integrada, estudos sobre clientes (satisfação do cliente, } \\
\text { estratégias de vendas, etc.), estudos sobre concorrentes, informatização das atividades } \\
\text { administrativas, desenvolvimento de produtos, informatização das atividades operacionais, } \\
\text { estratégias de terceirização }\end{array}$ \\
\hline Capacitação em Gestão Produtiva & $\begin{array}{l}\text { - Automação industrial; idade média dos equipamentos } \\
\text { - Programas de qualidade e produtividade (Q\&P) } \\
\text { - Certificados de qualidade }\end{array}$ \\
\hline Recursos Humanos & $\begin{array}{l}\text { - Categorias ocupacionais segundo escolaridade, número de ocupados } \\
\text { - Programas de treinamento e educação }\end{array}$ \\
\hline Uso de TICs & $\begin{array}{l}\text { - Uso de computadores; uso de redes de longo alcance integradas com clientes e } \\
\text { fornecedores; acesso à Internet; uso de comércio eletrônico }\end{array}$ \\
\hline Interação com o Sistema de CT\&I & $\begin{array}{l}\text { - Acordos de cooperação para o desenvolvimento de atividades de inovação/laboratórios e } \\
\text { centros de P\&D/Universidades e centros profissionalizantes/Institutos de pesquisa } \\
\text { governamentais }\end{array}$ \\
\hline $\begin{array}{l}\text { Interação e Cooperação na Cadeia } \\
\text { Produtiva }\end{array}$ & $\begin{array}{l}\text { - Desenvolvimento conjunto de processos e serviços } \\
\text { - Contratos de longo prazo } \\
\text { - Troca sistemática de informações sobre qualidade e desempenho } \\
\text { - Levantamento de informações sobre mudança no perfil do cliente }\end{array}$ \\
\hline
\end{tabular}

Fonte: Fundação Seade. Pesquisa da Atividade Econômica Paulista - Paep 2001.

ções sobre um conjunto de variáveis que permitem entender as dinâmicas de inovação com uma cesta de indicadores mais ampla que aquelas delimitadas pelas pesquisas sobre inovação tecnológica strictu sensu. Desse modo, os dados sobre difusão das TICs, estratégias de gestão de recursos humanos, instrumentos e métodos gerenciais, organização e requisitos de inserção em cadeias produtivas e qualificação de recursos humanos, entre outros, permitem uma abordagem mais ampla do processo de inovação, tal como defendida por Marklund (2000), integrando diversos enfoques que interagem no processo de inovação e difusão no setor de serviços (Quadro 5).

\section{EVIDÊNCIAS ESTATÍSTICAS SOBRE O COMPORTAMENTO DA INOVAÇÃO NA INDÚSTRIA E NO SETOR DE SERVIÇOS}

Estudos como o realizado por Schwartz et al. (2004), demonstram que o Estado de São Paulo é o principal centro das indústrias brasileiras em setores de alta tecnologia e de parte significativa dos serviços mais avançados, integrando os elos mais dinâmicos da cadeia produtiva dos setores ligados a TICs.

A partir da adoção da tipologia recomendada pela OCDE para o setor de TICs, demonstra-se o elevado o grau de 
concentração econômica regional no Estado de São Paulo em atividades que dão prioridade ao conhecimento e informação - tanto na indústria como no setor de serviços.

Com o objetivo de proporcionar uma demonstração empírica dos enunciados críticos suscitados neste artigo - as diferenças e convergências no comportamento setorial da inovação -, foi realizado um exercício preliminar utilizando a base de dados da Paep 2001, a partir dos dados das empresas sediadas no Estado de São Paulo com porte ocupacional de 20 ou mais pessoas. Este exercício focalizou tanto as atividades das empresas industriais como as de um conjunto selecionado do setor de serviços: agricultura, técnicos para empresas, auxiliares para empresas, transporte, telecomunicações, correio, informática, saúde, energia, gás e água, limpeza urbana/esgoto.

A Paep 2001 apresenta um universo de 13.645 empresas industriais e quase 21 mil do setor de serviços. Na indústria, 961 empresas afirmaram ter introduzido um novo produto para o mercado nacional - o que resultou em uma taxa de inovação da ordem de 7\%. No conjunto selecionado de atividades do setor de serviços, 923 responderam ter introduzido novos produtos e/ou processos para o mercado, perfazendo um resultado total da taxa de inovação de $5,6 \%$.

Como foi salientado por Viotti et al. (2005, p. 684) e Furtado (2004) o conceito de inovação para o mercado corresponde a um tipo de inovação mais próximo da idéia original de inovação schumpeteriana. Considerando o seu impacto no padrão de competitividade e na acumulação de capacitação tecnológica da empresa que a realiza, ela pode ser classificada como uma inovação qualitativamente superior àquelas que são novidades apenas para as em- presas, mas não o são para o mercado. Em contrapartida, as inovações que são pioneiras apenas para as empresas estão mais próximas do conceito schumpeteriano de difusão (ou absorção) tecnológica.

Seguindo essa linha de raciocínio, pode-se argumentar que as modestas performances das taxas de inovação setoriais devem-se ao peso reduzido das inovações originais ou criadoras na economia paulista. Além disso, essas taxas corroboram a hipótese de que o sistema paulista apresenta uma característica estrutural predominantemente estigmatizada por trajetórias de aprendizado tecnológico típicas de economias imitadoras e periféricas, nas quais a mudança técnica está associada basicamente à absorção e ao aperfeiçoamento de inovações geradas fora do país ou pela dinâmica de aquisição de tecnologia incorporada em bens de capital (QUADROS et al., 2004).

Tal como foi enfatizado na seção anterior, a partir da investigação de empresas inovadoras quanto à sua atuação na realização de atividades de P\&D (Tabela 1), observa-se que a indústria apresenta maior intensidade de rotinas $(48,9 \%)$ e de existência formal de laboratórios de P\&D $(39,2 \%)$, em comparação com o setor de serviços $(31,4 \%$ e $15,5 \%$, respectivamente). Ademais, as informações sobre subcontratação das atividades de P\&D revelam que esses expedientes são mais praticados pelo setor de serviços $(30,4 \%)$ do que pela indústria $(25,6 \%)$. O conjunto demonstra que as atividades de inovação e P\&D no setor de serviços não parecem ser necessariamente tão formalizadas e organizadas como na indústria, pois possuem características próprias e dinâmicas singulares em seu desenvolvimento e em sua execução, segundo os tipos dos serviços prestados, que as diferenciam das rotinas da indústria. É verdade também que, em muitos casos, o setor de serviços benefi-

TABELA 1

Empresas do Setor da Indústria e dos Serviços Selecionados, Inovadoras para o Mercado Nacional, segundo Indicadores das Atividades de Inovação Estado de São Paulo - 2001

\begin{tabular}{lcc}
\hline & & Em porcentagem \\
\hline Indicadores das Atividades de Inovação & Indústria & Serviços Selecionados \\
\hline Introduziram Produto e/ou Processo Novo para o Mercado Nacional & 7,1 & 4,6 \\
Realizaram Atividade de P\&D Sistemática ou Contínua & 48,9 \\
Contrataram Atividade de P\&D & 25,6 & 31,4 \\
Possuem Laboratórios de P\&D & 39,2 & 30,4 \\
Solicitaram Registro de Patentes/Copyright & 55,3 & 15,5 \\
\hline
\end{tabular}

Fonte: Fundação Seade. Pesquisa da Atividade Econômica Paulista - Paep 2001.

Nota: Empresas com 20 ou mais pessoas ocupadas sediadas no Estado de São Paulo. 
cia-se das atividades de $\mathrm{P} \& \mathrm{D}$ da indústria a partir da aquisição de um novo conhecimento ou tecnologia.

Conseqüentemente, é possível presenciar no setor de serviços uma relação causal menos efetiva entre as atividades internas de $\mathrm{P} \& \mathrm{D}$ e o lançamento de novos produtos para o mercado nacional do que a que pode ser constatada na indústria. A baixa socilitação de registro das inovações no setor de serviços $(25,2 \%)$ pode estar associada ao alto nível de intangibilidade dessas atividades - o que exige uma grande capacidade de compreensão e codificação dos sistemas complexos de serviços por parte dos recursos humanos envolvidos no processo de inovação. Além disso, os custos e o grau de incerteza incorporados a essas operações de registro de copyright acabam por inibir a própria aplicação de mecanismos de proteção da inovação, por isso, são menos utilizados pelas empresas inovadoras do setor de serviços.

Prosseguindo com o exercício analítico de "evidenciar padrões de comparabilidade tecnológicas entre indústria e serviços", sistematizou-se as informações do universo das empresas que compõem esses setores. Desagregadas por atividades, elas apontaram para as possíveis relações entre o grau de intensidade tecnológica setorial, ${ }^{16} \mathrm{o} \mathrm{com-}$ portamento da taxa de inovação, das rotinas de $\mathrm{P} \& \mathrm{D}$ e a difusão de computadores por pessoas ocupadas (Tabelas 2 e 3). Mesmo levando-se em conta o elevado grau de heterogeneidade, a distinção dos regimes de funcionamento econômico ou as dimensões relacionadas à intensidade e

TABELA 2

Empresas do Setor Industrial, por Taxa de Inovação, Atividades de P\&D, Intensidade Tecnológica e Difusão de Computadores, segundo Atividades Estado de São Paulo - 2001

\begin{tabular}{|c|c|c|c|c|c|}
\hline Atividades & $\begin{array}{l}\text { Taxa de } \\
\text { Inovação } \\
(1)(\%)\end{array}$ & $\begin{array}{l}\text { Realizaram } \\
\text { Atividade } \\
\text { Interna de } \\
\text { P\&D (\%) }\end{array}$ & $\begin{array}{c}\text { Contrataram } \\
\text { Atividade de } \\
\text { P\%D (\%) }\end{array}$ & $\begin{array}{l}\text { Intensidade } \\
\text { Tecnológica } \\
\text { (2) (\%) }\end{array}$ & $\begin{array}{c}\text { Densidade de } \\
\text { Pessoas por } \\
\text { Computador } \\
\text { (3) }\end{array}$ \\
\hline Indústria & 7,1 & 13,0 & 9,7 & 0,8 & 4,7 \\
\hline Indústria Extrativa & 2,3 & 4,0 & 13,6 & 0,3 & 10,2 \\
\hline Alimentos e Bebidas & 5,2 & 13,5 & 11,7 & 0,5 & 5,6 \\
\hline Produtos Têxteis & 3,5 & 8,7 & 6,1 & 0,3 & 8,5 \\
\hline Confecção de Vestuários e Acessórios & 0,7 & 5,2 & 5,5 & 0,4 & 9,5 \\
\hline Prepar. e Confecções de Artefatos de Couro & 3,6 & 10,5 & 11,3 & 0,3 & 10,4 \\
\hline Celulose e Papel & 4,6 & 13,5 & 7,5 & 0,4 & 4,4 \\
\hline Edição, Impressão, Reprodução de Gravações & 3,0 & 6,5 & 7,9 & 0,5 & 2,2 \\
\hline Refino de Petróleo e Álcool & 2,9 & 3,1 & 17,2 & 0,1 & 9,9 \\
\hline Produtos Químicos & 15,1 & 30,5 & 16,7 & 1,4 & 3,5 \\
\hline Artigos de Borracha e Plásticos & 5,7 & 12,9 & 9,5 & 0,6 & 6,3 \\
\hline Prod. Minerais Não-Metálicos & 4,6 & 10,4 & 10,7 & 0,5 & 7,8 \\
\hline Metalurgia Básica & 9,2 & 11,3 & 9,5 & 0,5 & 3,1 \\
\hline Produtos de Metal (Excl. Máq. e Eq.) & 6,5 & 9,8 & 10,5 & 0,4 & 5,3 \\
\hline Máquinas e Equipamentos & 16,5 & 15,9 & 9,1 & 0,9 & 4,0 \\
\hline $\begin{array}{l}\text { Máq. Escritório e Equipamentos de Informática } \\
\text { Máquinas, Aparelho e Material Elétrico }\end{array}$ & $\begin{array}{l}27,0 \\
11,1\end{array}$ & $\begin{array}{l}38,2 \\
21,8\end{array}$ & $\begin{array}{r}23,5 \\
9,5\end{array}$ & $\begin{array}{l}2,7 \\
0,9\end{array}$ & $\begin{array}{l}1,4 \\
3,8\end{array}$ \\
\hline Material Eletrônico e Aparelhos e Equipamentos de Comunicações & 20,2 & 31,5 & 19,0 & 4,3 & 2,3 \\
\hline $\begin{array}{l}\text { Equipamentos Médicos, Ótica e Relógios, Instrumentos de Precisão } \\
\text { e Automação Industrial }\end{array}$ & 19,4 & 32,8 & 16,7 & 3,1 & 3,1 \\
\hline Montagem de Veículos Automotores, Reboques e Carrocerias & 8,0 & 16,8 & 10,3 & 0,6 & 5,5 \\
\hline Outros Equipamentos de Transporte & 13,7 & 11,3 & 12,4 & 11,6 & 2,2 \\
\hline Outras Indústrias & 3,6 & 9,2 & 6,1 & 0,4 & 7,5 \\
\hline
\end{tabular}

Fonte: Fundação Seade. Pesquisa da Atividade Econômica Paulista - Paep 2001.

(1) Porcentagem de empresas que realizaram/introduziram inovação tecnológica para o mercado nacional, no período entre 1999 e 2001, em relação ao total de empresas do setor/atividade. (2) Número total de pessoas ocupadas de nível superior alocada em P\&D/número total de pessoas ocupadas no setor.

(3) Número de pessoal ocupado no setor/atividade dividido pelo número de equipamentos de informática (microcomputadores e terminais) alocado no mesmo. 
amplitude do impacto da inovação em termos de encadeamentos tecnológicos, observa-se que a principal evidência diz respeito às rotinas e estratégias de $\mathrm{P} \& \mathrm{D}$ praticadas nos dois setores. Os dados da Paep indicam que no setor de serviços a incidência de empresas que contrataram atividades de P\&D (11,1\%) em 2001 é superior às empresas que realizam essas atividades internamente $(6,5 \%)$ - in house, ao contrário do setor industrial (Tabela 2), onde a maior parte das empresas que realizam atividades de P\&D o fazem internamente $(13,0 \%)$ enquanto uma menor porcentagem $(9,7 \%)$ das empresas contrataram serviços externos de P\&D.

Em relação à diversidade intra-setorial, verifica-se, na Tabela 2, que aquelas atividades da indústria que expressam um comportamento mais elevado do indicador de intensidade tecnológica - bem acima da média do setor $(0,8 \%)$-, acabam por apresentar performances positivas quanto às taxas de inovação e rotinas internas de $\mathrm{P} \& \mathrm{D}$ assim como um padrão superior de difusão tecnológica, considerando-se a oferta de computadores por pessoas ocupadas. Nesse grupo, sobressaem-se quatro atividades: Outros Equipamentos de Transporte (11,6\%) - particularmente influenciada pelo setor aeronáutico, Material Eletrônico e Aparelhos e Equipamentos de Comunicações (4,3\%), Equipamentos Médicos, Instrumentos de Precisão e Automação Industrial $(3,1 \%)$ e Equipamentos de Informática $(2,7 \%)$. Saliente-se ainda a alta incidência da contratação externa das atividades de $\mathrm{P} \& \mathrm{D}$ praticada pelo setor de equipamentos de informática $(23,5 \%)$ e material eletrônico e de equipamentos de comunicações $(19,0 \%) .{ }^{17}$

Embora deva ser evidenciado o baixo dinamismo em relação à taxa de inovação e às atividades de $\mathrm{P} \& \mathrm{D}$ na análise sobre o comportamento de empresas inovadoras no setor de serviços, é importante ressaltar que estudos desenvolvidos por Miozzo e Soete (2001) têm enfatizado que, nas economias cêntricas, os serviços que priorizam conhecimento e ciência - os chamados KIBS - têm demonstrado uma notável propensão para a atividade exportadora ou trajetórias de internacionalização e inovação. Estudo recente realizado por Bernardes e Kalup (2005) baseado em informações da Paep 2001 e tendo como foco os serviços de telecomunicações, de P\&D, audiovisuais, informática e técnico às empresas, demonstrou que, ao contrário da experiência internacional, são poucos os serviços inovadores que realizam atividades exportadoras - sendo que a ampla maioria tem no mercado interno e local a sua principal fonte geradora de receitas. ${ }^{18}$ De modo geral, observa-se que, em todos os segmentos de serviços que realizam $P \& D$, a incidência de contratação externa é superior ao desenvolvimento interno dessas atividades nas empresas. Em segmentos como informática e telecomunicações, as taxas de inovação $(29,7 \%$ e $14,9 \%$, respectivamente) são muito próximas às incidências das atividades internas de P\&D (24,4\% e $14 \%$, respectivamente) e à sua contratação externa $(24,2 \%$ e $14,0 \%$, respectivamente). Já os indicadores de difusão tecnológica mostram maior oferta de computadores - em relação à média do setor $(3,1 \%)$ nos serviços intensivos no uso de TICs. São eles: serviços de telecomunicações $(0,6 \%)$; informática $(0,6 \%)$; técnicos às empresas $(1,4 \%)$ e energia, gás e água $(2,6 \%)$.

Os serviços de informática e os serviços técnicos às empresas apresentam os maiores níveis de intensidade tecnológica, 4,8\% e 2,0\%, respectivamente. Entretanto, esses dois segmentos merecem algumas considerações. Apesar do mercado de informática ser dominado por gigantes multinacionais (Microsoft, Unysis, Oracle, entre outras) existem nichos que oferecem oportunidades de atuação para as médias e pequenas empresas. Essas empresas de capital nacional disputam o mercado local de software em aplicativos de gestão empresarial e de inteligência de negócios, dispondo de substancial capacidade competitiva $^{19}$ para concorrer com as principais multinacionais instaladas em São Paulo e no Brasil.

No caso dos serviços técnicos para empresas, existe uma oferta diversificada de serviços de alta qualificação, entre elas os de $\mathrm{P} \& \mathrm{D}$, que exigem um determinado tipo de competência e expertise profissional e que passaram a ser intensamente demandados pelas empresas - sobretudo nos anos 90, com os expedientes de focalização dos negócios, de externalização das atividades empresariais e o ingresso de novos concorrentes na economia. Segundo Nählinder (2002, p. 4), as empresas de KIBS geralmente são estruturadas por carreers of knowledge, isto é, seus funcionários possuem uma alta graduação e conhecimento e seus produtos não podem ser gerados por máquinas. Ademais, a relação produção-cliente, devido à alta singularidade de cada produto e ao modus operandi da produção, é bem mais intensa nessas atividades. Sendo assim, esses funcionários são geralmente bem remunerados. Isso faz com que os salários sejam transformados em start-up para seus próprios empreendimentos (o que também não requer um alto capital inicial) e assim passam a ser competidores de seus antigos empregadores. Ressalte-se ainda que um seleto grupo das empresas pertencentes aos segmentos de engenharia e arquitetura ou escritórios de advoca- 


\section{TABELA 3}

Empresas do Setor de Serviços, por Taxa de Inovação, Atividades de P\&D, Intensidade Tecnológica e Difusão de Computadores, segundo Atividades

Estado de São Paulo - 2001

\begin{tabular}{|c|c|c|c|c|c|}
\hline Atividades & $\begin{array}{l}\text { Taxa de } \\
\text { Inovaçãa } \\
\text { (1) (\%) }\end{array}$ & $\begin{array}{l}\text { Realizaram } \\
\text { Atividade } \\
\text { Interna de } \\
\text { P\&D (\%) }\end{array}$ & $\begin{array}{c}\text { Contrataram } \\
\text { Atividade de } \\
\text { P\&D (\%) }\end{array}$ & $\begin{array}{c}\text { Intensidade } \\
\text { Tecnológica } \\
\text { (2) (\%) }\end{array}$ & $\begin{array}{c}\text { Densidade de } \\
\text { Pessoas por } \\
\text { Computador } \\
\text { (3) }\end{array}$ \\
\hline Serviços & 5,9 & 6,5 & 11,1 & 0,6 & 3,1 \\
\hline Agricultura & 3,2 & 4,2 & 0,5 & 0,2 & 20,8 \\
\hline Técnicos às Empresas & 5,1 & 4,5 & 19,0 & 2,0 & 1,4 \\
\hline Auxiliares às Empresas & 1,5 & 3,6 & 6,4 & 0,2 & 8,7 \\
\hline Transporte & 2,3 & 4,1 & 8,7 & 0,2 & 5,0 \\
\hline Telecomunicações & 14,9 & 14,0 & 14,0 & 0,7 & 0,6 \\
\hline Atividades de Informática & 29,7 & 24,4 & 24,2 & 4,8 & 0,6 \\
\hline Saúde & 7,3 & 6,6 & 8,0 & 0,5 & 5,3 \\
\hline Energia, Gás e Água & 4,9 & 12,7 & 15,3 & 0,8 & 2,6 \\
\hline Limpeza Urbana/Esgoto & 6,7 & 4,8 & 7,2 & 0,2 & 16,7 \\
\hline
\end{tabular}

Fonte: Fundação Seade. Pesquisa da Atividade Econômica Paulista - Paep 2001.

(1) Porcentagem de empresas que realizaram/introduziram inovação tecnológica para o mercado nacional, no período entre 1999 e 2001 , em relação ao total de empresas do setor/atividade.

(2) Número total de pessoas ocupadas de nivel superior alocada em P\&D/número total de pessoas ocupadas no setor.

(3) Número de pessoal ocupado no setor/atividade dividido pelo número de equipamentos de informática (microcomputadores e terminais) alocado no mesmo.

TABELA 4

Empresas da Indústria e dos Serviços, Inovadoras para o Mercado Nacional, segundo Importância das Fontes de Informação para o Desenvolvimento das Atividades de Inovação Tecnológica

Estado de São Paulo - 1999-2001

Em porcentagem

\begin{tabular}{lcc}
\hline Fontes de Informação & Indústria & Serviços \\
\hline Departamentos da Empresa & 63,45 & 80,11 \\
Outras Empresas Dentro do Grupo da Empresa & 23,44 & 43,19 \\
Fornecedores de Equipamentos, Materiais, Componentes ou Softwares & 60,17 & 73,96 \\
Clientes & 76,20 & 68,68 \\
Concorrentes & 50,27 & 44,40 \\
Empresas de Consultoria & 18,34 & 29,34 \\
Universidades e Outros Institutos de Educação Superior & 27,50 & 27,36 \\
Institutos de Pesquisa/Centros Profissionalizantes & 25,38 & 18,13 \\
Aquisição, Licenças, Patentes e Know-How & 30,78 & 20,66 \\
Conferências, Encontros e Publicações Especializadas & 39,59 & 50,77 \\
Feiras e Exposições & 56,10 & 45,49 \\
Departamentos de P\&D & 76,87 & - \\
\hline
\end{tabular}

Fonte: Fundação Seade. Pesquisa da Atividade Econômica Paulista - Paep 2001.

Nota: Considerou-se somente as variáveis "importante" e "muito importante" como fontes de informação para empresa inovar no período $1999 / 2001$. 
cia desfruta de prestígio no mercado internacional e exportam seus serviços.

Nos serviços de telecomunicações, observa-se que a taxa de inovação $(14,9 \%)$ apresenta o segundo melhor desempenho entre os serviços estudados, embora o indicador de intensidade tecnológica posicione-se mais próximo da média total do setor de serviços. Esse resultado deve-se à existência de duas concorrências dinâmicas e técnicas distintas. De um lado, toma-se como exemplo o segmento de telefonia fixa - onde há monopólio de oferta de serviços e uma moldura institucional de regulamentação pública que acabam por determinar um grau reduzido de contestabilidade do mercado, originando maior concentração econômica das empresas. Desse modo, nessas atividades, quem mais gera valor são as grandes empresas: elas são mais expressivas econômica e estruturalmente, e, por isso, são caracterizadas como prestadoras de serviços complexos e altamente custosos que necessitam elevados recursos tecnológicos. Por outro lado, no segmento de manutenção e assistência de telecomunicações, que é caracterizado por prestações de serviços de baixo conteúdo tecnológico, as oportunidades para as pequenas e médias é superior - o que esti- mula uma alta competitividade de mercado. Em sua maioria, essas empresas não realizam atividades de $P \& D$ e têm grande participação númerica nesse segmento. Dessa forma, acabam criando um impacto negativo no resultado do indicador de intensidade tecnológica.

Voltando a tratar das empresas inovadoras e considerando as fontes de informação como insumos críticos para os processos de desenvolvimento e implementação de inovações (Tabela 4) observa-se que, tanto na indústria como no setor de serviços, as principais fontes utilizadas evidenciam um movimento competitivo cada vez mais direcionado para os sinais de mercado.

Nesse sentido, os clientes despontam como variáveis críticas para os dois setores. Entretanto, as atividades internas de P\&D (in-house) parecem ser mais importantes para a indústria do que para o setor de serviços, que recorre às informações de outros departamentos da empresa ou mesmo do grupo (departamentos de marketing, de planejamento estratégico, entre outros).

Uma outra característica comum entre as empresas de serviços e as da indústria é que os fornecedores de equipamentos de materiais e softwares também constituem um importante insumo para o esforço inovador, embora haja

TABELA 5

Empresas do Setor de Serviços, Inovadoras e Não-Inovadoras para o Mercado Nacional, por Estratégias

Avançadas de Gestão Corporativa, segundo Atividades

Estado de São Paulo - 2001

Em porcentagem

\begin{tabular}{|c|c|c|c|c|c|c|}
\hline \multirow[b]{2}{*}{ Atividades } & \multicolumn{2}{|c|}{ Estudos sobre Clientes } & \multicolumn{2}{|c|}{$\begin{array}{l}\text { Estudos sobre } \\
\text { Concorrentes }\end{array}$} & \multicolumn{2}{|c|}{$\begin{array}{l}\text { Uso de Software de } \\
\text { Gestão Integrada }\end{array}$} \\
\hline & Inovadoras & $\begin{array}{c}\text { Não- } \\
\text { Inovadoras }\end{array}$ & Inovadoras & $\begin{array}{c}\text { Não- } \\
\text { Inovadoras }\end{array}$ & Inovadoras & $\begin{array}{c}\text { Não- } \\
\text { Inovadoras }\end{array}$ \\
\hline Setor de Serviços & 82,8 & 49,4 & 51,3 & 24,5 & 61,2 & 31,2 \\
\hline Agricultura & 66,7 & 32,1 & 16,7 & 20,1 & 0,0 & 6,0 \\
\hline Técnicos às Empresas & 61,7 & 35,6 & 37,2 & 21,5 & 78,7 & 33,9 \\
\hline Auxiliares às Empresas & 76,6 & 50,6 & 48,9 & 25,7 & 40,4 & 20,0 \\
\hline Transporte & 85,9 & 48,1 & 35,9 & 23,5 & 90,6 & 34,3 \\
\hline Telecomunicações & 94,4 & 57,3 & 44,4 & 39,8 & 94,4 & 35,9 \\
\hline Atividades de Informática & 95,5 & 84,6 & 63,3 & 42,0 & 55,2 & 54,9 \\
\hline Saúde & 72,1 & 50,2 & 47,1 & 14,7 & 53,8 & 39,5 \\
\hline Energia, Gás e Água & 46,2 & 55,3 & 38,5 & 41,6 & 30,8 & 34,1 \\
\hline Limpeza Urbana/Esgoto & 83,3 & 51,2 & 50,0 & 30,5 & 83,3 & 27,3 \\
\hline
\end{tabular}

Fonte: Fundação Seade. Pesquisa da Atividade Econômica Paulista - Paep 2001. 
indicações de que essa variável é mais valorizada no setor de serviços.

Por fim, as informações originárias das atividades de conferências, encontros e publicações especializadas e empresas de consultoria são mais utilizadas pelas empresas de serviços do que pela indústria.

Embora a metodologia recomendada pelo Manual de Oslo considere as mudanças gerenciais como não-inovações tecnológicas, há pesquisas internacionais que argumentam que as estratégias de marketing e as técnicas avançadas de gestão corporativa são conceitos críticos para o processo de inovação no setor de serviços. Em muitos casos, as pesquisas que visam à inovação nascem e são desenvolvidas nas áreas de inteligência de mercado e marketing (THOWKE, 2003). Os dados apresentados na Tabela 5 demonstram que, para as empresas inovadoras do setor de serviços, a combinação de estudos sobre os clientes $(82,8 \%)$, sobre os concorrentes $(51,3 \%)$ e o uso de softwares de gestão integrada $(61,2 \%)$ são elementos importantes para a compreensão da natureza da inovação nesse setor. Por este motivo, as pesquisas sobre inovação devem aprofundar seus estudos sobre essas variáveis.

\section{CONCLUSÕES}

Os resultados deste estudo são parte de um exercício preliminar e pioneiro sobre a natureza, o comportamento da inovação no setor de serviços e seus padrões de convergência e diferenciação tecnológica, tendo como referência a indústria paulista. A consecução dos objetivos propostos neste estudo foi viabilizada por meio da exploração da base de dados inédita produzida pela Paep 2001, que demonstra a grande vitalidade e multidimensionalidade das informações sobre a economia de serviços no Estado de São Paulo. As conclusões deste trabalho sugerem a importância da construção de indicadores de monitoramento das atividades de inovação, P\&D e difusão tecnológica nos serviços, como instrumento estratégico para as políticas de inovação e de desenvolvimento econômico. Considerando as características estruturais de segmentação e heterogeneidade do setor de serviços, observa-se a necessidade de promover estudos aprofundados para melhor compreender os padrões de funcionamento intra-setoriais e os fluxos econômicos e tecnológicos entre este setor e o industrial.

De modo geral, embora se verifique um baixo dinamismo nas atividades inovadoras no setor de serviços (um pouco maior naqueles com intensidade tecnológica superior), a experiência internacional revela que ele pode ser bastante inovador exportando e empregando recursos humanos de alta qualificação e renda.

No caso da economia paulista, esse comportamento pode ser explicado, em parte, porque as estratégias corporativas das grandes empresas vêm se pautando pela internalização ou desenvolvimento das competências essenciais para a sua competitividade. Em outros casos, porque compra, no mercado externo, soluções não encontradas localmente. Ademais, a própria fragilidade tecnológica e inovadora da indústria marcada pela baixa densidade das rotinas de P\&D gera pressões de demanda menos dinâmicas e exigentes para os serviços tecnológicos e intensivos em conhecimento. Entretanto, as informações da Paep 2001 e do estudo realizado por Bernardes e Kalup (2005) também mostraram que os serviços de informática, telecomunicações e técnicos às empresas apresentam um comportamento inovador sofisticado - e, em alguns casos, com performances bastante competitivas.

Sob a ótica do desenvolvimento e do fortalecimento da competitividade, os serviços intensivos em inovação e conhecimento são elementos estruturais de suporte que podem estimular o crescimento econômico e industrial, o comportamento inovador empresarial e a difusão de novas tecnologias. Nesse sentido, a formulação de políticas públicas de competitividade e inovação direcionadas para a promoção do desenvolvimento tecnológico e a internacionalização dos serviços - estimulando a reversão do déficit da balança de serviços -, assim como o fomento na articulação e integração com o setor industrial são estratégicas, podendo resultar no longo prazo em benefícios maiores para a economia em termos de geração de divisas, tecnologia, emprego e renda.

\section{NOTAS}

1. Organizações como a UN (United Nations): Unesco (United Nations Educational, Scientific and Cultural Organization) e UNCTAD (United Nations Conference on Trade and Development); o IDB (InterAmerican Development Bank) e a EC (European Commission), têm elaborado estudos de caráter conceitual, metodológico e operacional que servem de orientação e recomendação para a atuação dos países, com relação tanto à formulação e à avaliação de políticas como à produção de dados. Essas instituições vêm exercendo a liderança no processo de padronização de conceitos e métodos, bem como na construção de indicadores comparáveis internacionalmente. Ver, Porcaro (2004). 
2. Para uma revisão detalhada sobre o histórico metodológico das estatísticas de CT\&I, ver: Archibugi e Sirilli (2000); Bernardes (2003); Schwartz et al. (2004) e Porcaro (2004)

3. Ver: <http://www.nsf.gov/>

4. Para uma amostra sobre a produção científica baseada nesta pesquisa ver: Quadros et al. (1999); Costa (2003); Araújo (2001), entre outros.

5. As informações da Paep 1996 tiveram uma importante contribuição para a elaboração do segundo volume da série indicadores de Ciência, Tecnologia e Inovação para 2001 no Estado de São Paulo organizado pela Fundação de Amparo à Pesquisa do Estado de São Paulo - Fapesp. Esse estudo teve sua terceira versão publicada em 2005, tendo como ano-base 2004. As duas publicações estão disponibilizadas no site da Fapesp: 〈http://www.fapesp.br/indicadores/>.

6. Entre as iniciativas que contribuíram para o aperfeiçoamento desse campo metodológico, é digna de menção a discussão conceitual e institucional da mudança tecnológica e da organização P\&D no Brasil, promovida no âmbito do Diretório da Pesquisa Privada (DPP) e do Observatório de Estratégias para a Inovação (OEI). Um dos argumentos sustentados é o de que não basta ter unicamente uma estratégia alinhada em termos de pesquisa e desenvolvimento (P\&D), com investimentos volumosos e direcionados para áreas promissoras.

7. Calculam que os serviços transacionáveis baseados no conhecimento representavam $18 \%$ do valor adicionado (VA) total dos países membros da OCDE. Os correios, os serviços de telecomunicações e os serviços às empresas estão, em geral, entre os serviços transacionáveis mais utilizadores de tecnologia. Estes setores representavam cerca de $25 \%$ do VA na Suíça. Entre os países do G7, os EUA e o Reino Unido são os que apresentam os serviços com forte intensidade de conhecimento mais desenvolvidos.

8. Segundo Miles (1995), na primeira metade da década de 90, cerca de $80 \%$ dos investimentos em tecnologia de informação no Reino Unido e EUA são consumidos nos setores de serviços.

9. São definidas pelas atividades de serviço, indústria e comércio relacionadas com o processo de informação e comunicação por meios eletrônicos.

10. A origem do termo KIBS é pouco precisa, mas sabe-se que foi empregado pela primeira vez no projeto Innovation Programme Directorate General for Telecommunications, Information Market and Exploitation of Research financiado pela OCDE e conduzido por Miles (1995). Os KIBS podem ser agrupados em dois conjuntos: serviços usuários de novas tecnologias e serviços produtores de novas tecnologias. São exemplos do primeiro grupo os segmentos de engenharia, arquitetura, marketing, publicidade, consultorias financeiras e jurídicas, entre outros. Pertencem ao segundo grupo: as redes de informática, os serviços de telecomunicações, empresas de P\&D, entre outras

11. O debate e a própria compreensão sobre a natureza da inovação no setor de serviços foi fortemente influenciado pelo modelo do "ciclo reverso do produto" (CRP) proposto por Richard Barra's, que por sua vez, apresentava clara influência da abordagem neoschumpeteriana. Essa abordagem, considerada como determinística por autores como Uchupalanan (1998), Sundbo e Gallouj (2000), foi a iniciativa pioneira no sentido de formalização de uma teoria da inovação e aprendizado nas empresas de serviços a partir de uma perspectiva dinâmica e interativa. No CRP, a natureza das trajetórias tecnológicas de inovação e capacitação modificam-se em cada uma das três fases do seu ciclo de desenvolvimento. Tal modelo pressupõe que, em certos serviços como bancos, telecomunicações, informática, seguros, serviços de contabilidade e finanças, observase um ciclo de vida reverso ao ciclo de produto convencional da indústria. Nessa abordagem, o ponto central é o de que o setor serviços apropria-se, inicialmente, de novas tecnologias (na forma de aquisição de informações e sistemas computacionais e telemáticos) desenvolvidos pela indústria.
12. Os países são Bélgica, Alemanha, Dinamarca, França, Grécia, Itália, Irlanda, Luxemburgo, Holanda, Portugal, Espanha, Reino Unido e Noruega.

13. Seguindo a ótica dessas indagações, a Ricyt - Red Iberoamericana/ Interamericana de Indicadores de Ciencia y Tecnología desenvolveu o Manual de Bogotá (JARAMILLO et al., 2000), resultado de um esforço conjunto de pesquisadores latino-americanos para contornar dificuldades da adoção do Manual de Oslo em pesquisas de inovação na América Latina.

14. Nessa pesquisa foram excluídos os segmentos serviços domésticos, administração pública, serviços financeiros e condomínios.

15. Ressalte-se que o âmbito geral da Paep 2001 foi mais amplo do que aquele analisado neste artigo. Na Paep 2001 foram investigadas as empresas dos setores indústria e indústria da construção com mais de cinco pessoas ocupadas e todas as empresas, independentemente do número de pessoas ocupadas, do Comércio, dos Bancos e dos Serviços, com atividade no Estado de São Paulo. Não foram pesquisados os segmentos pertencentes às instituições financeiras, administração pública, serviços de condomínio e serviços domésticos. Neste sentido, o universo total da pesquisa foi de 792 mil empresas.

16. O indicador de intensidade tecnológica é uma proxy limitada sobre o esforço tecnológico realizado pelas empresas. É calculado pelo número de pessoas de nível superior alocadas em $\mathrm{P} \& \mathrm{D}$ em relação ao total do número de pessoas ocupadas no setor de atividade. $\mathrm{O}$ indicador desejável seria o cálculo entre os dispêndios em $\mathrm{P} \& \mathrm{D} /$ Valor de Transformação Industrial; entretanto, a Paep 2001 não dispõe dessas informações. A análise baseada nessas informações foi realizada em Quadros et al. (2004) e Furtado e Quadros (2005).

17. Um estudo realizado por Quadros et al. (2004) que utilizou informações da Pintec 2000 para o Estado de São Paulo sobre dispêndios das empresas inovadoras, captou o mesmo comportamento para o setor de material eletrônico, onde $20 \%$ dos dispêndios em atividades inovativas eram direcionados para a aquisição externa de P\&D. Os autores questionavam o resultado, argumentando que esse segmento é altamente apoiado por recursos e incentivos federais. Esse resultado seria até mesmo contraditório em relação às informações de fontes de inovação, onde verifica-se a pequena importância atribuída à cooperação tecnológica e às instituições externas para as atividades inovativas.

18. Ficou demonstrado que, embora apresentem individualmente uma expressão numérica modesta (17\% das empresas), o conjunto de serviços produtivos que dão prioridade à informação e ao conhecimento contribui com uma parcela relevante da atividade econômica, pois eles são responsáveis por $27 \%$ do VA do total dos serviços. Em média, seu perfil ocupacional apresenta níveis de qualificação mais elevado do que os do total do setor. A relação de ocupações de nível superior é mais elevada do que a das ocupações de nível médio. Os indicadores de difusão tecnológica também demonstram um padrão de intensidade superior ao observado para o conjunto dos serviços. Por exemplo, os indicadores de oferta de computadores, acesso a internet, home page e comércio eletrônico são bem superiores aos observados para o total de serviços (BERNARDES; KALUP, 2005).

19. As vantagens reveladas pelas empresas nacionais estão relacionadas as oportunidades de nichos de mercados decorrentes da oferta de serviços e soluções corporativas para o uso de tecnologias de informação baseadas em custos mais acessíveis e competitivos.

\section{REFERÊNCIAS BIBLIOGRÁFICAS}

ARAÚJO, M.F.I. Impactos da reestruturação produtiva sobre a Região Metropolitana de São Paulo no final do século XX. Tese (Doutorado) - IEA/Unicamp, Campinas, 2001. 
ARCHIBUGI, D.; SIRILLI, G. The direct measurement of technological innovation in business. National Research Council, Rome, Italy, 2000.

BALDWIN, J.R. et al. Innovation in Dynamic Service Industries. Statistics Canada. Ottawa. Dez. 1998.

BELL, D. The Coming of Pos-Industrial Society, a venture in social forescasting. New York: Basic Book, 1973.

BERNARDES, R. Produção de estatísticas e inovação tecnológica: Paep 1996-2001. São Paulo em Perspectiva, São Paulo, Fundação Seade, v. 17, n. 3-4, p. 151-167, jul./dez. 2003.

BERNARDES, R.; KALUP, A. A nova economia de serviços em São Paulo: setores produtivos intensivos em informação e conhecimento. São Paulo: Fundação Seade, out. 2005. (Relatório de Pesquisa).

BESSA, V.C.; TERCI, D.; NERY, M. Sociedade do conhecimento. São Paulo em Perspectiva, São Paulo, Fundação Seade, v. 17, n. 3-4, p. 3-16, jul./dez. 2003.

BONDEN, M.; MILES, I. Services and the knowledge-based economy. London and New York: Ed. Continuum, 2000.

CLARK, C. Las condiciones del Progresso Económico. Madrid: Alianza Editorial, 1980.

COSTA, I. Empresas multinacionais e capacitação tecnológica na indústria brasileira. 2003. Tese (Doutorado em Política Científica e Tecnológica) - Universidade Estadual de Campinas/Instituto de Geociências, Campinas. 2003.

DE NEGRI, J.A.; SALERNO, M.S. Inovações, padrões tecnológicos $e$ desempenho das firmas industriais brasileiras. Brasília: Ipea, 2005.

EVANGELISTA, R.; SAVONA, M. Patterns of innovation in services: the results of the Italian Innovation Survey. In: ANNUAL RESER CONFERENCE, 7th, Berlin. Paper... Berlin: 8-10 Oct. 1998.

EVANGELISTA, R.; SIRILLI, G.; SMITH, K. Measuring Innovation in Services. IDEA Paper, n. 6, Oslo, STEP Group, 1998.

FISHER, A.G. The Clash of Progress and Serenity. London: 1935.

FREEMAN, C.; CLARK, J.; SOETE, L. Unemployment and Technical Innovation. London, Frances Printer, 1982.

FUCHS, V.R. The Service Economy. National Bureau of Economics Research, 1968.

FURTADO, A.T.; QUADROS, R. Padrões de intensidade tecnológica da indústria brasileira: um estudo comparativo com os países centrais. São Paulo em Perspectiva, São Paulo, Fundação Seade, v. 19, n. 1, p. 70-84, jan./mar. 2005.

FURTADO, J. O comportamento inovador das empresas industriais no Brasil. Estudos e Pesquisas, Rio de Janeiro, n. 88, set. 2004.

GALLOUJ, F.; WEINSTEIN, O. Innovation in services. Research Policy, n. 26, p. 537-556, 1997.

GERSHUNY, J.; MILES, I. The New Service Economy. London: Frances Printer, 1983.

HAUKNES, J. Services in Innovation - Innovation in Services. Paris: OECD, Sept. 1999.

HIPP, C.; TETHER, B.; MILES, I. The incidence and effects of innovation in services: Evidence from Germany. International
Journal of Innovation Management, v. 4, n. 4, p. 417-454, Dec. 2000.

HOWELLS, J. Innovation \& Services: new conceptual frameworks. CRIC Discussion Paper, 38. The University of Manchester \& Umist. Aug. 2000

JARAMILLO, H.; LUGONES, G.; SALAZAR, M. Manual de Bogotá: normalización de indicadores de innovación tecnológica en América Latina y el Caribe. Bogotá, Colombia, 2000. (Proyecto financiado por la Organización de Estados Americanos OEA).

KANNEBLEY JUNIOR, S.; SILVEIRA PORTO, G.; TOLDO PAZELLO, E. Inovação na indústria brasileira: uma análise exploratória a partir da Pintec. Revista de Inovação Brasileira, v. 3, n. 1,2005

KON, A. Economia de Serviços - Teoria e Evolução no Brasil. Rio de Janeiro: Campus/Elsevier, 2004.

MARKLUND, G. Indicators of innovation activities in services. In: BONDEN, M.; MILES, I. Services and the knowledge-based economy. London and New York: Ed. Continuum, 2000.

MILES, I. Services Innovation: a reconfiguration of innovation studies. Prest Discussion Paper 01-05, University of Manchester, 2001.

Services Innovation: Statistical and Conceptual Issues. April 1995. Paper prepared for OECD/DSTI and presented at NESTI workshop (DSTI/EAS/STP/NESTI, (95)23).

MIOZZO, M; SOETE, L. Internationalization of Services: A Technological Perspective. Technological Forecasting and Social Change, n. 67, p. 159-185, 2001.

MOMIGLIANO, F.; SINISCALCO, D. Mutamenti nella strutura del sistema produttivo e integrazione tra industria e terziario. In: PASINETTI, L. (Ed.). Mutamenti Struturali Del Sistema Produtivo - integrazione tra industria e settore terziario. Mulino: 1986.

NÄHLINDER, J. Innovation in KIBS. State of art and conceptualisations. In: SIRP Seminar. England: Jan. 2002.

PORCARO, R.M. A informação estatística oficial na sociedade da informação: uma (des)construção. DataGramaZero - Revista de Ciência da Informação, v. 2, n. 2, abr. 2004. Disponível em: <http://www.dgz.org.br/abr01/Art_04.htm>.

QUADROS, R.; FURTADO, A.; BERNARDES, R.; FRANCO, E. Padrões de inovação tecnológica na indústria paulista: comparação com os países industrializados. São Paulo em Perspectiva, São Paulo, Fundação Seade, v. 13, n.1-2, p. 53-66, jan./jun. 1999.

QUADROS, R.; ARAÚJO, M.F.I.; BERNARDES, R.; FURTADO, A. Inovação tecnológica na indústria: uma análise com base nas informações da Pintec. In: FAPESP. Indicadores de Ciência, Tecnologia e Inovação em São Paulo. São Paulo: 2004. cap. 8.

SCHWARTZ, G. (Coord.).; BESSA, V. de C.; TERCI, D.C.; LEMOS, P.; BRITO, M. das G.M. Tecnologias de Informação e Comunicação (TICs) e Redes Digitais. In: FAPESP. Indicadores de Ciência, Tecnologia e Inovação em São Paulo. São Paulo: 2004. cap. 10.

SIRILI, G.; EVANGELISTA, R. Technological Innovation in Services and Manufacturing: results from Italian Surverys. In: SYSTEMS AND SERVICES INNOVATION WORKSHOP, CRIC, UNIVERSITY OF MANCHESTER, 17-18, Mar. 1998, forthcoming in Research Policy, 1988. 
SUNDBO, J.; GALLOUJ, F. Innovations as a Loosely Coupled System in Services. In: METCALFES, J.S.; MILES, I. (Ed.) Innovation Systems in the Services Economy: Measurement and Case Study Analysis. Boston: Kluwer Academic Publishers, 2000. p. 43-68.

THOWKE, S. P\&D chega aos serviços: experimentos revolucionários do Bank of America, Harward Business Review, v. 81, n. 4, abr. 2003.

TOURAINE, A. La société post-industrielle. Paris: Denoel, 1969.

UCHUPALANAN, K. Dynamics of competitive strategy and IT based innovation in banking services. International Journal of Innovation Management, v. 4, n. 4, p. 455-490, Dec. 2000.

VIOTTI, E.; BAESSA, A.R.; KOELLER, P. Perfil da inovação na indústria brasileira: uma comparação internacional. In: DE NEGRI, J.A.; SALERNO, M.S. Inovações, padrões tecnológicos e desempenho das firmas industriais brasileiras. Brasília: Ipea, 2005.
VIOTTI, E.; MACEDO, M.M.(Org.). Indicadores de ciência tecnologia e inovação no Brasil. Campinas, Ed. Unicamp, 2003.

Roberto Bernardes: Doutor em Sociologia pela USP, Professor Adjunto da Escola Superior de Propaganda e Marketing e Analista da Fundação Seade.

VAGner Bessa: Mestre em Geografia pela USP, Analista da Fundação Seade.

ANDRÉ KALuP: Bacharel em Turismo pela Universidade Anhembi Morumbi.

Artigo recebido em 2 de maio de 2005.

Aprovado em 6 de junho de 2005. 